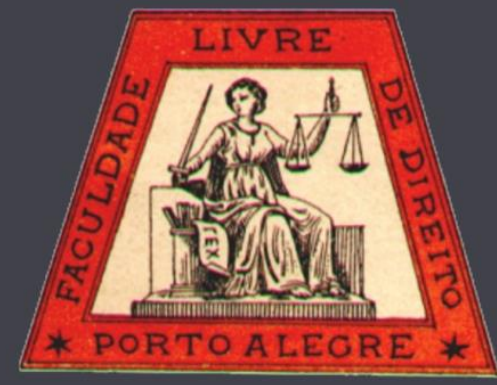

Temporalidade e refutabilidade dos conceitos políticos

Temporality and refutability of political concepts

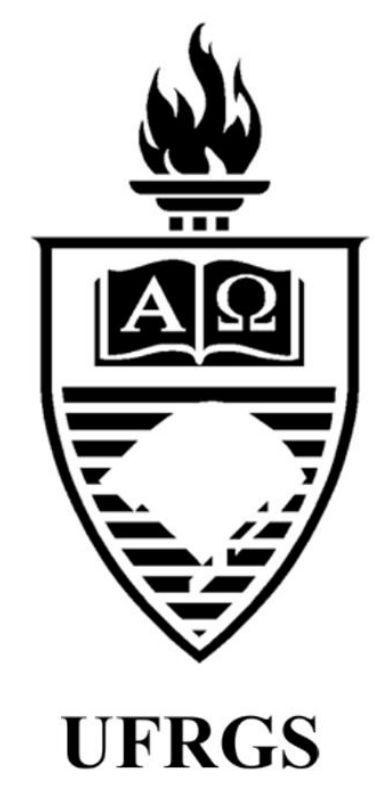

Elías José Palti Universidad Nacional de Quilmes Universidad de Buenos Aires 


\title{
Temporalidade e refutabilidade dos conceitos políticos*
}

\author{
Temporality and refutability of political concepts
}

Elías José Palti**

\section{REFERÊNCIA}

PALTI, Elias José. Temporalidade e refutabilidade dos conceitos políticos. Revista da Faculdade de Direito da UFRGS, Porto Alegre, n. 35, p. 4-23, dez. 2016.

\begin{abstract}
RESUMO
Nas últimas décadas, o conceito do "político" de Carl Schmmitt tem ressurgido nos debates sobre teoria política, e isso também teve importante repercussão no campo da história intelectual. A distinção entre politica e o político permitiu-nos reconsiderar a natureza de conceitos políticos, reavaliar a sua natureza controversa. Isso é visto agora como um resultado de sua indefinição. $O$ fato de que conceitos como democracia, justiça, liberdade, etc. não aceitam qualquer definição, que resistem a toda tentativa, nasceria da natureza intrinsecamente aporética deles, isto é, do fato de que eles não se referem a nenhum conjunto de ideias ou princípios que poderiam ser listados, mas sim que servem como índices de problemas. $\mathrm{O}$ presente artigo pretende rastrear essa transformação teórica no campo da história política-intelectual, suas consequências para a pesquisa histórica. E também como isso afetou nossos meios de abordar a história intelectual latino-americana.
\end{abstract}

\section{PALAVRAS-CHAVE}

História do Pensamento Político. História Intelectual. História do Pensamento Político Latino-americano.

\begin{abstract}
In the last decades, Carl Schmitt's concept of the political has resurface in the debates on political theory, and it has had important repercussion in the field of intellectual history, too. The distinction between politics and the political allowed us to reconsider the nature of political concepts, reassess their controversial nature. It is now seen as a result of their undefinability. The fact that concepts like democracy, justice, freedom, and so on, do not accept any definition, that resist all attempt, would spring from the intrinsically aporetic nature of them, that is, that they do not refer to any given set of ideas of principles that could be listed, but rather they serve as indexes of problems. The present article intends to trace this theoretical transformation in the field of political-intellectual history, its consequences for historical research. And also how this affect our ways of approaching Latin American intellectual history.
\end{abstract}

\section{KEYWORDS}

History of Political Thought. Intellectual History. History of Latin American Political Thought.

\section{SUMÁRIO}

Introdução; 1. A história dos conceitos e suas aporias constitutivas. 2. A revolução historiográfica de guerra e seus limites. 3. Transcendência e imanência no pensamento liberal republicano. 4. Coda: história de ideias, história de conceitos e história de linguagens políticas.

\begin{abstract}
A mudança produzida neste ramo da historiografia nas duas décadas passadas pode se caracterizar como um movimento que deixa de enfatizar a história do pensamento (ou, mais acentuadamente, "das ideias") e passa a enfatizar algo diferente, em relação ao qual "história da linguagem" ou "história do discurso",
\end{abstract}

embora nenhuma seja isenta de problemas nem irrepreensível, parece ser a melhor terminologia até então encontrada.

\footnotetext{
${ }^{*}$ Publicação original: PALTI, Elías José. Temporalidad y refutabilidad de los conceptos políticos. Prismas: revista de história intelectual, n. 9, p. 19-34, 2005. Tradução de Pedro Prazeres Fraga Pereira e Vicente de Azevedo Bastian Cortese. ** Professor da Universidad Nacional de Quilmes (Argentina) e da Universidad de Buenos Aires (Argentina). Investigador do Consejo Nacional de Investigaciones Científicas y Técnicas - CONICET.

${ }^{1}$ POCOCK, John Greville Agard. Virtue, commerce, and history: Essays on political thought and history, chiefly in the eighteenth century. Cambridge: Cambridge University Press, 1976.
} 


\section{INTRODUÇÃO}

Em um artigo recente, Terence Ball discute a tese da essencial refutabilidade (contestability) dos conceitos. ${ }^{2}$ Seguindo a máxima de Nietzsche segundo a qual "somente aquilo que não tem história é definível", os defensores de referida tese asseguram que o sentido dos conceitos medulares dos discursos ético, político e científico nunca podem fixar-se de um modo definitivo; isto é, que "não há nem pode haver critérios comuns compartilhados para decidir o que vale em estética por 'arte' ou em política por 'democracia' ou 'igualdade'. ${ }^{3}$ Esta tese, afirma Ball, resulta especialmente atrativa para os historiadores, posto que fornece uma chave para compreender as mudanças conceituais, de um modo, ademais, valorativamente neutro. A partir desta perspectiva, nenhuma teoria política poderia afirmar-se como superior ou mais verdadeira do que qualquer outra. $\mathrm{Na}$ realidade, segundo confessa, ele mesmo compartilhou-a por muito tempo, até que descobriu suas deficiências. ${ }^{4}$

Em primeiro lugar, afirma, implica uma falácia metodológica, uma vez que parte do fato contingente de que certos conceitos foram historicamente refutados (contested) para extrair daí uma lei universal acerca da natureza desses mesmos conceitos. Por outro lado, possui, ademais, implicações éticas negativas, dado que se não houvesse forma de fixar o sentido dos conceitos políticos fundamentais, se cada um pudesse interpretá-los à sua maneira, a própria ideia de comunidade se tornaria inconcebível.

2 A respeito, ver CONNOLLY, William. The terms of political discourse. Princeton: Princeton University Press, 1983.

3 BALL, Terence. Confessions of a conceptual historian. Finnish Yearbook of Political Thought, Jyväskylä, v. 6, n. 1, p. 11-31, 2002, p. 21.

4 O prólogo a Conceptual Change and the Constitution, que Ball escreve junto com Pocock, é, de fato, uma das defesas
Se os conceitos constitutivos do discurso político, e, portanto, da vida política, são de fato essencialmente refutáveis, então não poderia haver linguagem moral comum ou léxico cívico, e, por conseguinte, comunicação, e consequentemente comunidade inclusive sequer esperança de estabelecer e manter uma comunidade cívica. Se a tese da refutabilidade essencial fosse certa, então o discurso político, e, portanto, a vida política, tornar-se-ia impossível, e exatamente pelas mesmas razões que a civilidade e a vida social são impossíveis no estado de natureza imaginário e solipsista de Hobbes: cada indivíduo é uma mônada, radicalmente desconectado de qualquer outro indivíduo na medida em que exprime uma espécie de linguagem privada de sua própria fatura. Como essas linguagens individuais não podem traduzir-se ou entender-se mutuamente, cada falante é forçosamente um estranho e um inimigo para os demais. ${ }^{5}$

Em última instância, afirma, a tese mencionada tem consequências autoritárias. Caso sobrevenham desacordos a respeito do sentido de conceitos tais como "poder", "liberdade", justiça", etc., o entendimento mútuo seria alcançado unicamente por dois meios: a conversão ou a coerção; "e presumivelmente aqueles que não podem ser convertidos devem ser coagidos (excluídos, silenciados, ridicularizados, ignorados, etc.)". 6 Conforme veremos, o argumento de Ball permite estabelecer uma distinção fundamental. Sem embargo, é também ali que se fazem manifestas aquelas deficiências inerentes à própria história de "conceitos", as quais derivam, em última instância, de uma noção de temporalidade que a reduz a uma mera ocorrência fática.

mais eloquentes em favor de tal tese. Cf. BALL, Terence; POCOCK, John Greville Agard. (orgs.). Conceptual Change and the Constitution. Lawrence: Kansas University Press, 1998, p. 1-12.

5 BALL, Terence. Confessions of a conceptual historian. Finnish Yearbook of Political Thought, Jyväskylä, v. 6, n. 1, p. 11-31, 2002, p. 24.

6 Ibid., p. 23. 
1 A HISTÓRIA DOS CONCEITOS E SUAS APORIAS CONSTITUTIVAS

Ball assinala, com efeito, um ponto fundamental, mesmo que a forma em que o formula não resulte de todo apropriada. Está claro que afirmar que a tese da essencial refutabilidade dos conceitos conduz a uma espécie de solipsismo, tornando impossível toda forma de comunicação, é exagerado e, em última instância, errôneo. $\mathrm{O}$ que dita tese salienta é a impossibilidade de uma comunidade constituir-se plenamente como uma totalidade orgânica, perfeitamente integrada e homogênea. Como afirma Pocock, toda sociedade relativamente complexa alberga pluralidade de códigos ou linguagens políticos. ${ }^{7} \mathrm{O}$ certo é que a tese da essencial refutabilidade dos conceitos não nega, em princípio, a possibilidade de fixar o sentido desses conceitos, mas afirma que só é possível fazê-lo dentro dos marcos de uma determinada comunidade política ou linguística. ${ }^{8}$

Assim formulada, os desacordos a respeito dessa tese perdem sua aparência intransponível. $\mathrm{Na}$ realidade, Ball não ignora que os conceitos mudam seu sentido de acordo com o contexto de enunciação. Seria simplista ver seu argumento como propondo um simples retorno ao tipo de 'ahistoricismo' próprio da antiga tradição da história das “ideias". O ponto de controvérsia aqui repousaria em outro lado: se é ou não possível a mútua tradutibilidade entre os diversos tipos de discurso. Em todo caso, e considerando que as posturas a respeito variam ${ }^{9}$, não seria impossível

7 POCOCK, John Greville Agard. Introduction: the state of the art. In: Virtue, Commerce, and History. Essays on political thought and history, chiefly in the eighteenth century. Cambridge: Cambridge University Press, 1991, p. $1-36$.

8 Quem sustentou essa afirmação de um modo mais sistemático foi FISH, Stanley Eugene. Is there a text in this class? The authority of interpretive communities. Cambridge: Harvard University Press, 1980.

9 Para um ponto de vista oposto ao de Fish, veja-se BEVIR, Mark. ¿Hay problemas perennes en teoría política? Res publica, Madri, num. 11-12, p. 7-26, 2003, p. 7-26. reconciliá-las, encontrar algum termo médio aceitável entre os extremos de "plena continuidade" e "radical incomensurabilidade".

Não obstante, apresentadas as coisas deste modo, dilui-se o núcleo da disputa. Mesmo a perspectiva da impossível tradutibilidade mútua dos conceitos segue sendo uma expressão débil da ideia de indefinibilidade de que falava Nietzsche. Ball está correto, aqui, quando afirma que a tese mencionada tem implícita uma premissa mais "forte", que é aquela que, em última instância, ele rechaça. De acordo ela, não só toda fixação de sentido seria inevitavelmente parcial, relativa a uma linguagem particular, como seria, ademais, sempre precária. E isso por causas que remetem menos ao contexto histórico externo em que se desenvolveram as linguagens do que a razões muito mais inerentes, intrínsecas ("essenciais") a tais linguagens. Um artigo de Sandro Chignola resulta ilustrativo a respeito. ${ }^{10}$

No aludido artigo, Chignola distingue duas etapas no desenvolvimento recente da história conceitual italiana. A primeira aparece centrada ao redor de Perangelo Schiera e do Instituto Ítalo-Germánico de Trento, que nos anos 1970 renovaram de maneira decisiva os enfoques relativos à história constitucional. ${ }^{11}$ Seu modelo interpretativo, de matriz hintzeana, ${ }^{12}$ permitiu a revalorização do elemento linguístico na articulação das relações políticas, enfatizando assim a necessidade de historicizar os conceitos a fim de proceder a uma reconstrução mais precisa, típico-ideal, da experiência políticoconstitucional moderna.

10 CHIGNOLA, Sandro. Historia de los conceptos, historia constitucional, filosofía política. Sobre el problema del léxico político moderno. Res publica, Madri, num. 11-12, p. 27-67, 2003, p. 27-67.

11 As ideias historiográficas desta geração de autores se encontram condensadas em SCHIERA, Pierangelo (org.). Per una nuova storia constituzionale e sociale. Nápoles: Vita e Pensiero, 1970.

12 O livro de SCHIERA, Pierangelo. Otto Hintze. Nápoles: Tecniche Nuove, 1974 foi chave na difusão das ideias históricas deste último autor na Itália. 
Uma segunda vertente historiográfica, identificada com a obra do "Grupo de Investigación de los Conceptos Políticos Modernos", dirigido por Giuseppe Duso no Instituto de Filosofia da Universidade de Padua, haverá, sem embargo, de ir além, reformulando o sentido da própria história conceitual. ${ }^{13}$ Segunda afirma esta escola, para descobrir o sentido das categorias políticas modernas não basta traçar largas genealogias conceituais, analisando os distintos sentidos que adotaram os conceitos, e historicizar seus usos. O que se requer é, ademais, uma tarefa de "crítica e desconstrução". "Se os conceitos políticos modernos possuem uma historicidade específica", insiste Chignola, então "será possível reabrir a discussão em torno deles e de seu intrínseco caráter aporético". ${ }^{14}$

Como vemos, ambas correntes acordam em relação à ideia de temporalidade dos conceitos. Sem embargo, tomam como base duas visões muitos distintas a respeito dela. Para a primeira, o postulado que o sentido dos conceitos não pode fixar-se de um modo definitivo surge do rechaço aos pressupostos evolucionistas implícitos na velha história das ideias. Esta primeira fase na temporalização dos conceitos se propõe a revelar que as mudanças semânticas ocorridas ao largo do tempo não seguem um padrão determinado, orientado a realização de uma meta preestabelecida: a iluminação da verdadeira definição de um dado conceito. Sem embargo, a indefinibilidade dos conceitos se encontra ali associada ainda a fatores de ordem estritamente empírica. Indica uma condição fática, um acontecimento circunstancial. Nada impede, em princípio, que os conceitos possam fixar seu conteúdo semântico. Não há nada intrínseco a eles que nos permita anunciar ou

13 A respeito, veja-se BIRAL, Alessandro. Per una storia del moderno concetto di politica: genesi e sviluppo della separazione tra politico e sociale. Pádua: CLEUP, 1977; DUSO, Giuseppe (ed.). Il potere: per la storia della filosofia politica moderna. Roma: Carocci, 1999 e DUSO, entender por que as definições estabelecidas sobrevêm instáveis e, chegado o momento, sucumbem. A historicidade é aqui contingente e inevitável ao mesmo tempo. Os conceitos, definitivamente, mudam de sentido com o tempo, mas a historicidade não lhes é uma dimensão constitutiva. Para dizê-lo nos termos de Ball, os conceitos são sempre refutados, mas isso não significa que sejam essencialmente refutáveis. Partindo-se desta perspectiva, se não ocorre a ninguém questionar-lhe significado, tais conceitos poderiam sustentar-se indefinidamente.

O desenvolvimento de uma perspectiva mais "forte" relativa à temporalidade dos conceitos supõe um deslocamento da fonte da contingência, sua transposição do "contexto externo" ao interior da própria história intelectual. $\mathrm{Na}$ verdade, de acordo com esta segunda perspectiva, o fato de os conceitos não poderem estabelecer seu significado não é uma comprovação meramente empírica; refere a uma condição inerente a estes conceitos. Assinala o fato de que seus conteúdos semânticos nunca conformam um sistema racional e logicamente integrado. Quem melhor a definiu foi Hans Blumenberg, quando discute a teoria da secularização. Para ele, o que a modernidade herda das antigas escatologias não é nenhuma séria de conteúdos ideais traduzidos em chave secular, senão, fundamentalmente, um vazio. As cosmovisões cristãs não aportaram respostas à pergunta a respeito do sentido do mundo, frente a qual, sem embargo, a modernidade não poderia permanecer indiferente. Definitivamente, as diversas linguagens políticas não são senão outros tantos intentos de preencher significativamente esse vazio, tratar de alcançar, tornar inteligível, criar sentidos a fim de tornar suportável um

Giuseppe. La logica del potere: storia concettuale come filosofia politica. Roma: Latterza, 2007.

14 CHIGNOLA, Sandro. Historia de los conceptos, historia constitucional, filosofía política. Sobre el problema del léxico político moderno. Res publica, Madri, num. 11-12, p. 27-67, 2003, p. 35. 
mundo que, perdida toda ideia de transcendência, não pode, sem embargo, deixar de confrontar o impensável para aqueles: a radical contingencia ("irracionalidade") dos fundamentos de toda ordem secular; enfim, a "essencial refutabilidade" das categorias nucleares de todo discurso ético ou político moderno.

Isso implica que, mesmo no caso improvável - e, no longo prazo, definitivamente impossível - de que não mude o sentido de um conceito, este continuará sendo, de todos os modos, sempre refutável, por natureza. Encontramos assim uma interpretação diferente da máxima de Nietzsche: não se trata de que os conceitos não podem definir-se de um modo determinado porque seu sentido varia historicamente, mas do contrário: os conceitos modificam-se porque não podem ser definidos de um modo determinado. Não obstante, para compreender por que toda fixação de sentido é constitutivamente precária, devemos reconstruir um inteiro campo semântico, ir além da história dos conceitos em direção a uma história das linguagens políticas. Recriar uma linguagem política envolve não apenas a tarefa de traçar como os conceitos mudaram de significado ao largo do tempo, mas também, e fundamentalmente, a de compreender o que os impedia de alcançar sua completude semântica, descobrir aqueles pontos de fissura que lhes eram inerentes.

Isto é, mais precisamente, o que, em sua conferência inaugural no Collége de France, Pierre Rosanvallon chamou de "uma história conceitual do político". Segundo afirmou então, a visão formalista, típico-ideal, que vê as formações conceituais como sistemas autossuficientes e logicamente estruturados, esconde um impulso normativo que desloca o objeto histórico particular para recoloca-lo em um sistema de

15 ROSANVALLON, Pierre. Por una historia conceptual de lo político: lección inaugural en el Collége de France. referenciais ético-políticos. Desta forma, afirma, deixa escapar, precisamente, a "coisa mesma" do político, que é, assegura, sua essência aporética. O argumento de Ball é uma boa mostra dos impulsos normativos que subjazem as perspectivas débeis da temporalidade dos conceitos políticos. A ideia de Rosanvallon de uma "história conceitual do político" leva a inverter seu argumento a respeito do assunto. Não seria realmente a impossibilidade de fixar o sentido dos conceitos políticos o que faria a política impossível. Pelo contrário, se o significado de conceitos tais como justiça, democracia, liberdade, etc. pudessem estabelecerse de um modo objetivo, a política perderia ipso facto todo sentido. Em tal caso, a resolução dos assuntos públicos deveria ser confiada aos expertos. Não haveria lugar, enfim, para as diferenças legítimas de opiniões a respeito; só existiriam aqueles que conhecem essa verdadeira definição e aqueles que a ignoram.

O ponto, nas palavras de Rosanvallon, não é "buscar resolver o enigma [da política moderna] impondo-lhe uma normatividade, como se uma ciência pura da linguagem ou do direito pudesse indicar aos homens aquela solução razoável à qual não teriam outro remédio senão adequarem-se, mas de "considerar seu caráter problemático" a fim de "compreender seu funcionamento". ${ }^{15} \mathrm{E}$ isso implica uma reformulação fundamental dos modos de abordar a história político-intelectual. Segundo afirma: “O objetivo já não é apenas opor banalmente o universo das práticas ao das normas. Trata-se de partir das antinomias constitutivas do político, antinomias cujo caráter se revela unicamente no transcurso da história". ${ }^{16}$

Encontramos aqui, exposta em forma condensada, uma segunda formulação da natureza dos desacordos entre ambas correntes. Enquanto a primeira delas situa a fonte do estigma da

Buenos Aires: Fondo de Cultura Económica, 2003, p. 4142.

16 Ibid., p. 43. 
temporalidade que possuem os conceitos na brecha ineliminável entre as normas e as práticas concretas, para a outra, isso resulta de antinomias constitutivas da política. A fonte externa da temporalidade (a distância entre normas e práticas) remete, em última instância, e torna manifesta aquela outra forma de temporalidade alojada no interior das formações conceituais. Assim formulada, a controvérsia muda sua natureza (em última instância, o núcleo do desacordo entre estas duas escolas refere-se à definição do próprio desacordo). A mesma não se refere já a diferenças situadas em um mesmo nível de realidade, as quais poderiam, portanto, ser formuladas em termos de mais ou menos. Já não há aqui termo médio possível. Em suma, as duas correntes que Chignola observa no desenvolvimento recente da historia intelectual italiana ilustram uma oscilação característica na história conceitual, segundo hoje se pratica. Enquanto a primeira devolve esta a uma situação na qual se aproxima da velha história das ideias, ${ }^{17}$ a segunda traslada a disciplina a um terreno completamente novo e distinto, abrindo um horizonte ao que caberia chamar mais propriamente de uma história das linguagens políticas.

Como a intervenção de Ball mostra claramente, por trás da primeira das perspectivas analisadas se pode descobrir a persistência do tipo de aspirações normativistas próprias dos enfoques tipicamente filosóficos ou sobre as crenças do passado. A história intelectual latino-americana do século XIX nos oferece alguns exemplos das consequências para a investigação histórica da persistência destes impulsos normativistas.

17 Um bom exemplo desta convergência espontânea entre esta forma de compreender a história conceitual e a mais tradicional própria da história das ideiais se encontra em VEIT-BRAUSE, Irmline. The Interdisciplinarity of History of Concepts. A Bridge Between Disciplines. History of Concepts Newsletter, Nova Iorque, 6, p. 8-13, 2003, p. 813.

18 "A linguagem - assegura - não é uma realidade separável das realidades sociais, um elenco de instrumentos
Definitivamente, como veremos, tal compreensão normativista leva a que se reduza as controvérsias do passado relativas ao significado dos conceitos políticos meramente a uma série de lamentáveis mal-entendidos quanto ao sentido da política moderna, impedindo assim que se capte a natureza irremediavelmente dilemática das questões as quais os autores passados tiveram que confrontar.

\section{A REVOLUÇÃO HISTORIOGRÁFICA DE GUERRA E SEUS LIMITES}

$\mathrm{Na}$ revalorização do papel da dimensão simbólica nos processos históricos na historiografia latino-americana, a obra de François-Xavier Guerra representa um marco fundamental. ${ }^{18}$ Guerra resgataria assim a história intelectual do local de prostração em que a havia conduzido a velha escola de história de "ideias" organizada em torno da obra de Leopoldo Zea e a chamada "filosofia latino-americana". Como se comprova em seu livro Modernidad $e$ independência, ${ }^{19}$ esta perspectiva mais atenta às alterações ocorridas nos vocabulários políticos, aplicada ao início do século XIX, permite reformular de um modo crucial as visões relativas às crises de independência.

Em primeiro lugar, Guerra rompe com o esquema das "influências ideológicas". O que desencadeia a mutação cultural que analisa não é tanto a leitura de livros importados, mas a série de transformações que alteram objetivamente as condições de enunciação dos discursos. Como assinala, a convergência com a França ao nível das linguagens políticas "não se trata de

neutros e atemporais do qual se pode dispor à vontade, mas sim uma parte essencial da realidade humana." $\mathrm{Cf}$. GUERRA, François-Xavier. Los espacios públicos en Iberoamérica: Ambigüedades y problemas. Siglos XVIIIXIX. México: Fondo de Cultura Economica, 1998, p. 8. 19 GUERRA, François-Xavier. Modernidad $e$ independencias. Ensayos sobre las revoluciones hispânicas. México: FCE, 1993. 
fenômenos de modas ou influências - ainda que estes também existam - mas, fundamentalmente, de uma mesma lógica surgida de um comum nascimento à política moderna [a "modernidade de ruptura"]". ${ }^{20}$ Guerra descobre assim um vínculo interno entre ambos níveis (o discursivo e o extra-discursivo). O "contexto" deixa de ser um cenário externo para o desenvolvimento das "ideias", e passa a constituir um aspecto inerente aos discursos, determinando desde dentro a lógica de sua articulação. E isso conduz ao segundo deslocamento produzido.

Em segundo lugar, Guerra conecta as transformações conceituais com alterações produzidas no nível das práticas políticas associadas com a emergência de novos âmbitos de sociabilidade e sujeitos políticos. Os deslocamentos semânticos observados adquirem sentido em função de seus novos meios e lugares de articulação, os quais não preexistem à própria crise política, mas surgem como seu resultado, e permitem a conformação de uma incipiente "esfera pública".

Em terceiro lugar, o que foi exposto abre a Guerra as portas para superar o dualismo entre tradicionalismo espanhol e liberalismo americano. Como ele mostra claramente, se trato de um processo revolucionário único, que abarcava em conjunto o Império, e tinha seu epicentro, precisamente, na península, que é a que se viu, de fato, mais diretamente impactada pela crise do sistema monárquico.

Em quarto lugar, esta perspectiva recoloca as visões a respeito dos modos de inscrição das guerras de independência na América Latina no marco da chamada "era das revoluções democráticas", e as peculiaridades da modernização hispânica (que Guerra inclui dentro da categoria de "modernidade de ruptura"). Seu traço característico será, de forma mais notável nas províncias ultramarinas - menos diretamente afetadas pelas novidades introduzidas por Cádiz uma conjunção de modernidade política e arcaísmo social que se expressa na hibridez da linguagem política, que superpõe referências culturais modernas com categorias e valores que remetem claramente a imaginários tradicionais.

Neste último ponto encontramos, sem embargo, o aspecto mais problemático de seu enfoque. Guerra termina ali chegando, por uma via distinta a de Reinhart Koselleck, a sua própria versão do que este denominou Sattelzeit (o período de ruptura conceitual em cujo curso se redefiniram todas as categorias políticas fundamentais, dando lugar à emergência de um vocabulário político moderno). Sem embargo, em Guerra esta questão se resolve em uma perspectiva dicotômica que opõe modernidade e tradição, como se se tratasse de duas totalidades coerentes, claramente delimitadas e homogêneas, o que reinscreve seu modelo dentro do mesmo marco de aproximações formalistas que Rosanvallon criticava.

Tal esquema interpretativo coloca, com efeito, dois problemas básicos. Em primeiro lugar, tem implícita a pressuposição de que na história intelectual ocidental houve uma única mutação conceitual, que é a que se produziu desde finais do séc. XVIII, e se para tradição de modernidade. E isso leva a descartar de antemão a possibilidade de qualquer outra ruptura subsequente (ou precedente). Tudo o que vem depois da quebra mencionada será assim agrupado sob uma etiqueta comum: a de "modernidade". Deste modo, terminam-se confundindo formações conceituais demasiado heterogêneas entre si para que resultem compreensíveis dentro de uma única categoria. $\mathrm{O}$ segundo problema, muito mais sério, é consequência do anterior. Na medida em que modernidade e tradição aparecem como blocos antinômicos perfeitamente coerentes e opostos 
entre si, as contradições na história intelectual serão vistas necessariamente como resultado de uma sorte de assincronia conceitual, a superposição acidental de duas épocas históricas diversas. Tudo o que se afaste do "tipo ideal" liberal não pode ser interpretado como algo diferente da persistência de visões tradicionalistas que se negam obstinadamente a desaparecer (gerando assim toda classe de hibridismos e patologias conceituais).

O marco explicativo dicotômico no qual Guerra faz repousar suas análises históricas (as quais, sem embargo, excedem decididamente, e não deixam de rebelar-se contra dito marco) esconde, na realidade, uma falácia metodológica, pela qual os termos invocados - modernidade e tradição - deixam de ser categorias históricas para se converterem no que Koselleck chama contraconceitos assimétricos, em que um dos quais se define por oposição ao outro, como sua contraface negativa. ${ }^{21}$ Considerados como designando simplesmente períodos históricos determinados, não excluem a presença de muitos outros. Não é assim, por outro lado, quando se convertem em contra-conceitos assimétricos, como ocorre, por exemplo, com democracia e autoritarismo. Neste caso, tudo o que não é moderno é necessariamente tradicional, e vice-versa. Ambos termos esgotam o universo imaginável do político. E, deste modo, perdem seu caráter histórico para se converter numa sorte de princípios trans-históricos que atravessariam inteiramente a história conceitual local e explicariam todo seu transcurso até o presente.

Chegamos assim ao núcleo do esquema interpretativo de Guerra. Para ele, o que a elite governante latino-americana fracassou em compreender não é o suposto sentido eterno da ideia de democracia - ele não crê na existência de

21 KOSELLECK, Reinhart. The historical-political semantics of asymmetric counterconcepts. In: Futures past: On the semantics of historical time. Cambridge: The MIT Press, p. 159-197, 1985, p. 159-197 [Tradução para o conceitos ternos -, mas sim o verdadeiro sentido da “democracia moderna. Este é também o ponto em que a perspectiva de Guerra se torna ilustrativa de dilemas teóricos de alcance mais vasto, que não afetam especificamente a história intelectual latino-americana, mas a disciplina enquanto tal. Definitivamente, por trás da falácia metodológica antes mencionada podemos descobrir os efeitos da persistência nela_de impulsos normativistas. Estes_não são incompatíveis com a ideia de temporalidade dos conceitos. Não obstante, a fim de dar lugar a invocações ético-políticas substantivas, tal ideia deve conter uma ambiguidade. Por um lado, os conceitos hão de ser vistos como contingentes, no sentido de que seu significado varia ao largo do tempo e, por tanto, as ideias de uma época não poderiam ser transpostas a outra. Sem embargo, por outro lado, os conceitos não seriam concebidos como verdadeiramente contingentes no sentido de que, considerados em seus próprios termos, estes apareceriam como perfeitamente autocontidos e autoconsistentes, isto é, como entidades logicamente integradas, e não historicamente articuladas.

Este último pressuposto resulta incompatível com a ideia de temporalidade dos conceitos somente nos marcos de uma determinada interpretação desta temporalidade. Como mostra Chignola em relação ao caso italiano, esta supõe um desenvolvimento subsequente na trajetória contemporânea da história conceitual; marca uma segunda fase, a qual envolve um trabalho adicional de "crítica e desconstrução". Definitivamente, na medida em que as formações conceituais seguem sendo vistas como horizontes auto-integrados e autoconsistentes, a recaída no tipo de visões normativistas próprias da tradição da filosofia

espanhol: Reinhart Koselleck, "Sobre a semântica históricopolítica dos conceitos contrários assimétricos", em Futuro passado. Para una semántica de los tiempos históricos, Barcelona, Paidós, 1993, p. 205-250]. 
política resulta inevitável; os desacordos a respeito do significado das categorias nucleares de um sistema de pensamento aparecerão inevitavelmente como expressões de alguma sorte de mal-entendidos, não como sua dimensão constitutiva.

Resulta significativo, por outro lado, observar que, como minha investigação sobre o século XIX mexicano demonstra, embora, em seu intento de tornar inteligível a crise que se abre imediatamente antes da independência, os próprios atores do período tenham se aferrado, em princípio, ao velho tópico das "ideias fora de lugar" (que explica as contradições encontradas no intento de implantar ideias estranhar à realidade local), haveriam, chegado o momento, de perceber as limitações daqueles modelos interpretativos que situam a origem da historicidade das linguagens políticas, a fonte da contingência e mutabilidade das formações conceituais, exclusivamente no se meio de aplicação, no "contexto histórico externo". À medida que se foi aprofundando a crise haveriam assim de descobrir, confusos, a presença de contradições que já não poderiam atribuir à persistência de padrões tradicionalistas herdados da colônia. O processo de inscrição da temporalidade no pensamento político atravessará então um segundo umbral, que transpassará o âmbito meramente empírico, para alojar-se no próprio conceito. Este começará a revelar assim suas aporias inerentes.

\section{TRANSCENDÊNCIA E IMANÊNCIA NO PENSAMENTO LIBERAL-REPUBLICANO.}

A definição de Pocock do "momento maquiavélico" provê a base para a percepção de um vínculo interno entre tempo e história conceitual. Segundo afirma:

O "momento maquiavélico" [...] é um nome para o
momento no tempo conceitualizado no qual a
república se vê confrontada com a sua própria
finitude temporal, como tentando manter-se moral e
politicamente estável em um fluxo de
acontecimentos irracionais, concebidos como
essencialmente destrutivos de todo o sistema de
estabilidade secular ${ }^{22}$.

Pocock associa aqui, pois, o surgimento do republicanismo clássico com a emergência da ideia da contingência na história (a fortuna). Chegamos assim a uma das chaves para compreender a diferença entre ideias e linguagens políticas. A linguagem republicana, para Pocock, diferentemente dos "tipos ideais", não pode ser definida por nenhum conjunto de máximas ou princípios. Tal linguagem consiste, basicamente, na definição de um problema. O "momento maquiavélico" designa, enfim, uma contradição: a tentativa de realizar valores universais (transcendentes) por meios seculares finitos (a república), os quais estão sujeitos, portanto, à corrupção ${ }^{23}$. Em outros termos, referida linguagem marca o momento da erupção da temporalidade no discurso político, o ponto em que o pensamento político enfrenta a evidência da contingência de toda organização institucional secular.

A aplicação de referido conceito ao caso latino-americano ajuda a compreender melhor as

existia para realizar para todos os cidadãos tudo o que o homem era capaz de realizar nesta vida, e particular, no sentido de que era finita e localizada no tempo e no espaço", em POCOCK, John Greville Agard. The Machiavellian moment: Florentine political thought and the Atlantic republican tradition. Princeton: Princeton University Press, 1975, cit., p. 3 
vicissitudes pelas quais passou o pensamento local do século XIX. Inversamente, a análise do caso local suscita inevitavelmente problemas e questionamentos relativos a aspectos metodológicos mais gerais que permitem reformular ou enriquecer dito modelo analítico. Segundo tento demonstrar em meu estudo intitulado A invenção de uma legitimidade ${ }^{24}$, a história do pensamento político mexicano do século XIX revela perspectivas novas fundamentais no que denominamos o processo de inscrição da temporalidade no discurso político de uma época dada (a inserção nesse de um elemento estranho à sua lógica imanente e que acaba por deslocá-la). Como veremos aqui sucintamente, a definição de Pocock do "momento maquiavélico" engloba e oculta diferenças cruciais quanto aos modos de conceber o caráter e a fonte da contingência que ameaça a estabilidade de toda ordem mundana. Referido momento maquiavélico seria, na realidade, apenas uma das formas possíveis de conceber tal contingência, marcaria unicamente um primeiro estágio no processo de deslocamento do vocabulário político liberal-republicano.

Algo que Pocock não assinala é que aquela contradição, tipicamente republicana-clássica, entre valores universais transcendentes (os únicos que podiam, em uma sociedade do Antigo Regime, justificar a existência de uma comunidade) e meios finitos imanentes se resolveria, em princípio, uma vez que se abandona, com o liberalismo, o ideal de realização de valores universais, para vincular a legitimidade dos sistemas políticos à própria vontade de seus membros; é dizer, quando se secularizam tanto meios quanto fins. Produz-se assim um deslocamento conceitual por meio do qual o âmbito da política se expande para compreender

24 PALTI, Elías José. La invención de una legitimidad: razón y retórica en el pensamiento mexicano del siglo XIX: un estudio sobre las formas del discurso político. México: Fondo de Cultura Economica, 2005, em edição. também o reino dos valores e das normas. Estas deixam de aparecer como meramente dadas (transcendentes, universais) para converterem-se em produtos das próprias decisões coletivas voluntariamente assumidas. Sem embargo, com a imanentização das concepções do "bem" (seu translado ao âmbito subjetivo-político), surgirá outra forma de historicidade, uma que escapa ao âmbito do "momento maquiavélico". Uma vez perdida toda instância de transcendência, a ideia liberal-republicana (que distinguiremos da republicana clássica) revelará uma aporia intrínseca ao seu próprio conceito; é dizer, dará lugar a um tipo de temporalidade imanentemente gerada, que não resulta dos embates de fatos irracionais que ameaçam a ordem institucional desde fora - a fortuna- senão de suas próprias contradições inerentes. Com efeito, o crescente clima de antagonismo que se desencadeou no México após a quebra do vínculo colonial terminaria revelando aquele fundo de contingência (irracionalidade) presente nos próprios fundamentos de toda ordem institucional pós-tradicional (já privada, portando, de toda garantia transcendente). A temporalidade (historicidade) se transladaria então do contexto ao próprio conceito. Ela rompe a sua reclusão no mundo para penetrar o reino dos valores.

A questão crítica que desencadeia a sucessão concatenação de pronunciamentos e em torno da qual girarão todos os debates políticos do período será a do alcance e dos limites do direito legítimo de insurreição ou de resistência à opressão (como assinala Alfonso Noriega, "o tema da resistência à opressão, ou do direito de insurreição, apaixonou os liberais ilustrados [mexicanos]"). ${ }^{25}$ Em última instância, o direito de insurreição minava a objetividade do ordenamento institucional, tornando a avaliação

25 NORIEGA, Alfonso. El pensamiento conservador y el conservadurismo mexicano. México: UNAM, 1993, t. I, p. 136. 
de sua legitimidade uma questão subjetiva, o que resultava destrutivo a dito ordenamento. A necessidade de sua limitação aparecerá assim como algo urgente, e, sem embargo, tornar-se-ia, ao mesmo tempo, crescentemente problemático de se alcançar (problemática de ser atingida). Sua definição no sistema jurídico mexicano do século XIX pela figura do "delito de opinião" revela desde já as ambiguidades que acarretava a sua tipificação como um crime. De fato, tal direito não só estava na base do regime republicano e distinguia esse do antigo despotismo, senão que se encontrava na própria origem do México como nação independente (nascida, não se pode esquecer, de uma revolução). Eé aqui que aparece aquele aspecto em que a análise do caso mexicano nos obriga a nos afastarmos da proposta original de Pocock.

No que podemos chamar (retomando os termos de Ernesto Laclau) ${ }^{26}$ uma "lógica de contingencia" (que é uma das formas possíveis de aludir ao que Pocock chama a "temporalização" do pensamento político), o "maquiavélico" representaria apenas um primeiro momento. Nele, a historicidade ainda aparece como exterior às normas. A partir de seus marcos, os problemas que a república confronta (perenidade, viabilidade, etc.) aparecem, todavia, como que remetendo a razões de ordem empírica, isto é, relativas ao âmbito de sua realização prática. $\mathrm{O}$ "momento maquiavélico" se articula, todavia, de fato, sobre a base da oposição platônica entre forma (morphē) e matéria (hyle) (que é a que subjaz à antinomia entre virtú e fortuna). O único tipo de temporalidade concebível dentro do conceito republicano clássico é o que deriva dessa oposição, isto é, vincula-se com a ideia da corruptibilidade da matéria criada. Em última instância, tal concepção é indissociável das visões teocêntricas do mundo.
$\mathrm{Na}$ medida em que o conceito liberalrepublicano conserva um momento de transcendência (a verdade das normas constitucionais), ainda podemos falar de um "momento maquiavélico" nele. A validade de referidas normas (o tipo ideal) não é, todavia, posta em questão, senão apenas a sua "aplicabilidade" a contextos e circunstâncias particulares, como o latino-americano. Sem embargo, como assinalamos, isso apenas marcaria um primeiro estágio na problematização de tal conceito. Esse desdobrar-se-á no México em três fases ou períodos sucessivos. Tais períodos se encontram separados por três acontecimentos que assinalaram, respectivamente, pontos de inflexão na história política local, determinando umbrais progressivos na dissolução do conceito de legitimidade.

O primeiro destes acontecimentos é representado pelo Motín de la acordada (1828), que quebra pela primeira vez a continuidade institucional do regime republicano surgido em 1824, e culmina em 1836 com a sanção das Sete Leis Constitucionais. Esta é, mais especificamente, a "Era de Mora". Ela assinala "o momento maquiavélico" na história do pensamento político mexicano. A quebra de ordem institucional produzida em 1828 e a sucessão dos levantes militares que lhe seguiu tornaria impossível distinguir um governo legítimo de outro ilegítimo (e, como consequência, decidir sobre a justiça o não dos levantes). Segundo a conclusão de Mora feita ao final de sua trajetória política, a questão já havia se tornado indecidível no México: neste ponto, estava claro que, para o governo, os insurrectos seriam sempre e inevitavelmente subversivos à ordem legitimamente estabelecida, e, inversamente, para os rebeldes, seria sempre o governo quem teria violado a constituição, cuja vigência eles, segundo alegavam, propunham-se restaurar, não havendo mais bases objetivas sobre

26 LACLAU, Ernesto. New Reflections on the Revolution our Time. Londres: Verso, 1990. 
as quais resolver a questão. Ainda assim, isso não lançaria, todavia, dúvidas a respeito da existência de critérios objetivos em princípio válidos para tanto. A contingência se refere aqui somente ao que na teoria jurídica se denomina adjudicatio, isto é, a aplicabilidade de uma norma geral a um caso particular.

O período seguinte se inicia com a revisão da carta constitucional e o fim da Primeira República Federal. A partir de 1836 começaria a revelar-se certa impossibilidade inerente ao conceito liberal-republicano para delimitar o exercício legítimo do direito de insurreição. Como assinala o porta-voz das forças centralistas, Francisco Manuel Sánchez de Tagle, "[a licitude do direito de insurreição] é o PONTO CENTRAL dessa questão; o ponto que ninguém resolveu [...]. Blackstone diz: "por que me pede regras, se a essência da revolução é não tê-las?'. Todos, enfim, perdem-se no mundo de vaguezas e nos deixam às escuras". ${ }^{27}$

O direito de insurreição aparece assim como o Outro da Lei, aquele que escapa radicalmente de seu âmbito. A impossibilidade de estabelecer critérios para limitar o direito de insurreição se revela como um limite interno à Lei (de fato, nenhuma constituição pode regulamentar a sua própria violação). Isso marca, enfim, um novo estágio na inscrição da temporalidade no conceito liberal-republicano: a indecidibilidade ultrapassa então o âmbito meramente empírico para alojar-se no seio do próprio conceito da Lei. Entramos no que chamaremos o "momento hobbeseano".

A desintegração progressiva do sistema político empurraria, sem embargo, este processo de irrupção da temporalidade um estágio adiante, no qual haveria de dissolver-se o conceito de legitimidade. Tal fato expressa no plano dos

27 SÁNCHEZ DE TAGLE, Francisco Manuel. Refutación de las especies vertidas en los números 21, 22, $23 \mathrm{del}$ periódico titulado El Anteojo contra el proyecto de la primera ley constitucional, que presentó al Congreso la discursos a situação de completa desintegração do sistema político (a ruptura do consenso de debate) produzida pela derrota militar ante os Estados Unidos em 1847, e que chega a por em questão a própria entidade do México como nação (abrindo, de fato, a perspectiva certa de sua completa desintegração territorial). Em tal contexto, o líder conservador Lucas Alamán desvendará o fundo aporético em que se sustenta o conceito liberalrepublicano. $^{28}$

Segundo mostra Alamán, o direito de insurreição é, com efeito, a negação da Lei, porém constitui, ao mesmo tempo, seu pressuposto. Em definitivo, é o exercício desse direito, destrutivo de toda ordem institucional, que torna manifesto o caráter soberano do cidadão em que todo regime republicano de governo (privado já de toda sanção transcendente) funda a sua legitimidade. Alamán aponta assim a uma contradição inerente ao conceito moderno de cidadão. Para constituir uma ordem legal, e poder ser efetivamente soberano, o cidadão deve renunciar ao exercício do direito de insurreição, porque, em caso contrário, estamos ainda em um estado de natureza. Porém se renuncia a esse direito, deixa ipso facto de ser soberano, o que não só representa uma contradição em termos, senão que, deste modo, privaria também de bases de legitimidade um sistema fundado, nesse caso, em uma soberania já inexistente (com o que também voltamos ao estado de natureza). Em síntese, o sistema liberalrepublicano pressupõe o exercício permanente desse mesmo direito que o torna impossível. O direito de insurreição se revela como a destruição e ao mesmo tempo o fundamento da Lei, o que a nega porém que $(* * *)$ encontra, sem embargo, em sua base, seu "exterior constitutivo".

Entramos aqui no que chamamos o “momento rousseauneano". Alamán e os

Comisión de Reorganización. México: Imprenta del Águila, 1835 , p. 21.

28 Conferir PALTI, Elías José. La Política Del Disenso: La Polémica en Torno Al Monarquismo México, 1848-1850. México: Fondo de Cultura Economica, 1998. 
conservadores forçariam então a elite mexicana a confrontar aquele impensável dentro dos marcos do pensamento liberal-republicano: a radical contingencia (indecidibilidade) dos fundamentos de toda ordem institucional pós-tradicional. A noção de legitimidade já não seria somente inviável no México - uma anomalia explicável somente como expressão de alguma "peculiaridade local" -; esta revelar-se-ia como uma categoria carente de sentido, algo ilusório. ${ }^{29}$

Podemos voltar agora ao argumento de Ball. É certo que, como ele assinala, não basta observar mudanças históricas nos conceitos, demostrar o fato de que eles sempre foram refutados, para deduzir disso a sua essencial refutabilidade. Porém isso apenas destaca as limitações próprias da história dos conceitos. A pergunta que aqui se propõe não é sobre as mudanças históricas de sentido. A questão da refutabilidade não pode ser resolvida meramente mediante a comprovação das transformações históricas contingentemente produzidas no sentido dos conceitos (procedimento intelectual que, como assinala Ball, contém uma falácia metodológica, uma espécie de salto ilegítimo do plano fático ao plano normativo ou ontológico). Tal questão suscita a interrogação a respeito de por que estas transformações se produzem, como elas são possíveis. Deste modo, desloca o nosso enfoque a um plano mais primitivo da realidade conceitual. A busca do que Chignola denomina

\footnotetext{
29 A expressão zombeteira de Alamán é eloquente quanto a isso: "Um escritor filósofo - referia - de demasiada celebridade por desgraça no século passado [Voltaire], dizia tratando do colegiado dos Oráculos da Roma antiga, composto pelos primeiros homens da república, que não compreendia como quando se reuniam para realizar a adivinhação e os presságios, que para tudo se consultavam, podiam olhar-se uns aos outros cara a cara sem rirem-se. Entre nós, pode-se dizer o mesmo com respeito à palavra legitimidade, a qual já não é fácil de ser pronunciada seriamente neste país, depois de tudo o que ocorreu no pós 1828. A farsa que os Oráculos romanos representavam, não era a seus próprios olhos, porém, outra coisa além de uma medida política com a qual se dava sanção do céu aos atos da autoridade, o que não enganava nenhum homem de juízo,
}

uma forma de historicidade imanente aos discursos - que faz deles entidades plenamente históricas, formações simbólicas totalmente contingentes -, e não meramente um subproduto acidental da "história social", para falar nos termos de Koselleck, reorienta nosso olhar a uma segunda ordem da realidade simbólica, que é o que designamos com o nome de linguagens políticas: as condições de produçãodesarticulação dos discursos.

A questão da temporalidade dos discursos contém, em definitivo, outra ainda mais fundamental, porém sintomaticamente ignorada nos presentes debates metodológicos: o que é uma linguagem política, como identificá-la, em que difere de um "sistema de ideias". Ainda que não possamos, nesse trabalho, esgotar todos os aspectos aqui contidos, gostaria de assinalar brevemente os traços cruciais que identificam as linguagens políticas e as distinguem dos sistemas de ideias.

\section{CODA: HISTÓRIA DE IDEIAS, HISTÓRIA DE CONCEITOS E HISTÓRIA DE LINGUAGENS POLÍTICAS}

1. Em primeiro lugar, as linguagens políticas não são meros conjuntos de ideias. Daí a avaliação repetida pelos historiadores de que tais linguagens resistem obstinadamente a toda definição, que o seu conteúdo não pode ser estabelecido de um

nem impediu a Cicero burlar os adivinhos em seu tratado sobre a Adivinhação; porém entre nós os mesmos que atropelaram toda a eleição constitucional, os que tudo transformaram por meio da força de revoluções, são os que gritam mais intensamente em favor da legitimidade e os que qualificam tudo de ilegítimo, com exceção, não obstante, de si mesmos e de seus amigos. Na última época, sobretudo, nada tem subsistido do modo conforme fora estabelecido em razão da constituição". Cf. ALAMÁN, Lucas; INCLÁN, Luis Gonzaga. Defensa del ex-Ministro de Relaciones $d$. Lucas Alaman, en la causa formada contra él y contra los ex-Ministros de Guerra y Justicia del Vice-Presidente d. Anastasio Bustamante: con unas noticias preliminares que dan idea del orígen de esta. Documentos Diversos. (Inéditos e muito raros). México: Jus, 1945. Tomo III, p. 118 
modo inequívoco. Ela é assim simplesmente porque uma linguagem política não consiste em nenhuma série de enunciados (conteúdos de discurso) que possam ser listados, senão em um modo característico de produzi-los. As linguagens políticas são, pois, indeterminadas semanticamente; nelas se pode sempre afirmar algo, e também o contrário. Em definitivo, estes remetem a um plano de realidade simbólica de segunda ordem, ao modo de produção dos conceitos. Nos termos elaborados por Jesús Mosterín, uma linguagem política é composta de conceitores (conceitos de conceitos). ${ }^{30}$ Para fazer uma história das linguagens políticas é necessário, pois, ultrapassar o plano textual, os conteúdos semânticos dos discursos (o plano das "ideias") e penetrar o dispositivo argumentativo que lhes subjaz e identifica, os modos ou princípios formais particulares da sua articulação.

2. O ponto precedente nos permite discernir os conteúdos de discurso das linguagens políticas subjacentes. O primeiro remete ao plano semântico; o segundo, à ordem sintática, aos dispositivos formais ou modos de produção dos discursos. Dessa perspectiva, falar, por exemplo, de uma linguagem liberal não tem sentido, se entendermos essa em termos estritamente ideológicos: pode-se ser liberal (ou conservador) de muitas maneiras diferentes. De fato, os mesmos postulados políticos podem responder a muitas diversas matrizes conceituais; e, inversamente, programas políticos muito diversos, e ainda contraditórios entre si, podem responder a uma mesma matriz conceitual. As continuidades no nível da superfície de ideias podem assim muito bem esconder descontinuidades fundamentais em relação às linguagens políticas subjacentes, e vice-versa (daí que, como vimos, o

30 Conferir MOSTERÍN, Jesús. Conceptos y teorías en la ciencia. Alianza, 1984. Esse epistemólogo alemão é membro do assim denominado "círculo de Berlin", liderado por Wolfgang Stegmüller. Referido grupo elaborou a chamada "concepção não enunciativa das teorias que importe não seja simplesmente entender o que um autor disse, senão penetrar a instância de suas afirmações explícitas e acessar a estrutura argumentativa que lhe é subjacente). E ele nos conduz a nosso segundo plano. As linguagens políticas cruzam o espectro ideológico. Esse é o significado da afirmação segundo a qual as linguagens políticas são entidades objetivas. Diferentemente das "ideias", não são atributos subjetivos; ditas linguagens articulam redes discursivas que tornam possível a mútua confrontação de ideais. E ele contém uma reformulação ainda mais radical dos enfoques tradicionais na história intelectual.

Os historiadores de ideias buscam estabelecer os conceitos fundamentais que definem cada corrente de pensamento e traçar horizontalmente a sua evolução ao longo do período considerado (como se se tratassem de entidades geradas independentemente e apenas $a$ posteriori justapostas). As linguagens políticas, por outro lado, apenas podem ser descobertas atravessando verticalmente as distintas correntes de pensamento. Estas se tornam relevantes unicamente na medida em que nos revelam, em sua interação, o conjunto de premissas compartilhadas sobre as quais se articula o discurso público de uma época, e como estas premissas se vão alternando no curso do tempo. Em síntese, para fazer uma história das linguagens políticas não basta, como dissemos, transcender a superfície textual dos discursos e acessar o aparato argumentativo que subjaz a cada forma de discursividade política; para fazê-lo, devemos reconstruir contextos de debate. O que importa aqui não é observar como mudaram as ideias, senão como se reconfigura o sistema de suas posições relativas, os deslocamentos nas coordenadas que determinam os modos de sua

científicas", a qual reformulará de modo crucial a noção de Kuhn de paradigma, dando assim um novo impulso aos estudos em filosofia da ciência. A perspectiva que aqui se expõe é, em boa parte, devedora dos aportes realizados por essa escola. 
articulação púbica. E esses não podem ser descobertos senão na mútua oposição entre perspectivas antagônicas.

3. A reconstrução dos contextos de debate não implica, sem embargo, sair do plano dos discursos. As linguagens políticas, de fato, transcendem a oposição entre texto e contexto em que a história de ideais se encontrava inevitavelmente presa. $^{31}$ Uma linguagem política assim se torna apenas na medida em que contém dentro de si as suas próprias condições de enunciação. Isso nos conduz, novamente, mais além do plano semântico da linguagem, que é o único objeto concebível para a história de ideias; nos leva, desta vez, a penetrar na dimensão pragmática dos discursos (quem fala, a quem se fala, como o faz, em que contexto social - relações de poder -, etc.) ${ }^{32}$, é dizer, nos propõe a necessidade de analisar como as condições de anunciação se inscrevem no interior do âmbito simbólico e passam a formar uma dimensão constitutiva dele. Para resumir o visto até aqui, fazer uma história das linguagens políticas supõe, não só transcender a superfície textual dos discursos e acessar o aparato argumentativo que subjaz a cada forma de discursividade política, buscando reconstruir contextos de debate. Para isso, precisamos recuperar os rastros linguísticos presentes nos

\footnotetext{
31 Como assinala Pocock, a oposição entre "texto" e "contexto", própria da história de ideias, conduz necessariamente a um círculo argumentativo. "O slogan ele diz - de que as ideias deveriam ser estudadas em seu contexto social e político corre, para mim, o risco de converter-se em puro palavrório. A maioria dos que o pronunciam supõem, geralmente inconscientemente, que eles já sabem qual é a relação entre as ideias e a realidade social. Comumente toma a forma de uma teoria crua da correspondência: supõe-se que as ideias estudadas são características daquela facção, classe ou grupo ao qual seu autor pertencia, e explica-se como tais ideias expressam os interesses, esperanças, medos ou racionalizações típicas de dito grupo. O perigo aqui é o de argumentar em círculos. De fato, é sumamente difícil identificar sem ambiguidade a adstrição social de um indivíduo, e ainda muito mais a de uma ideia - sendo a consciência algo sempre tão contraditório - e o sujeito tende a sustentar as suposições
}

próprios discursos dentro de seu contexto de enunciação.

Basicamente, esses três pontos assinalados orientam a superação das limitações da história de ideias, revelando-as como resultantes de uma visão crua da linguagem, que a reduz a sua instância meramente referencial. A nova história intelectual buscaria, por outro lado, abordar simultaneamente as três dimensões inerentes a todo uso público da linguagem: a semântica, a sintática e a pragmática. Podemos dizer, esquematicamente, que um ponto de vista radicalmente novo da história intelectual (o giro das ideias e das linguagens) surge das elaborações convergentes das três grandes correntes que atualmente dominam o campo, cada uma das quais enfatizaria, e renovaria nossas perspectivas, a respeito de cada uma dessas dimensões (a escola alemã de Begriffsgeschichte, para la semântica; a escola de Cambridge, para a gramática; e a nova escola francesa de história conceitual da política, para a sintática). Na medida em que combinamos seus respectivos aportes, obtemos o aspecto crucial que distingue as linguagens políticas dos sistemas de ideias, e que constitui o tópico específico do presente trabalho: os primeiros, diferentemente dos segundos, são entidades plenamente históricas, formações conceituais

que faz a respeito da posição social de dito pensador com as suposições que faz da significação social de suas ideias, e logo a repetir o procedimento na direção contraria produzindo uma definitivamente deplorável perversão metodológica", em POCOCK, John Greville Agard. Politics, language, and time: Essays on political thought and history. Chicago: University of Chicago Press, 1989, p. 105.

32 Estas eram, precisamente, as perguntas quintessencialmente retóricas que definem a possibilidade dos discursos: as chamadas circunstâncias. A sistematização das circunstâncias foi um dos principais feitos da tratadística retórica medieval. Partindo de Cícero e os clássicos, definiram-se então um conjunto de relações entre os fatores de discurso - circunstâncias - aos quais se referiam mediante perguntas específicas: quis (quem), quid (o que), cur (por que), ubi (onde), quando (quando), quemadmodum (como) e quibus adminiculs (de que forma). 
estritamente contingentes. E isso deve ser interpretado em um duplo sentido.

4. Em primeiro lugar, as linguagens políticas determinam um princípio de irreversibilidade temporal que lhes é intrínseco (e não meramente algo que lhes vem de fora, de seu contexto exterior), o qual se desdobra simultaneamente em uma direção dupla, é dizer, tanto prospectivamente como retrospectivamente. Àquilo que Skinner batizou como "mitologia da prolepse" (a busca pela significação retrospectiva de uma obra, o que pressupõe a presença de um certo telos significativo nela implícito e que somente no futuro se revela) devemos assim adicionar uma forma de mitologia inversa, que podemos denominar "mitologia da retroprolepse", isto é, a ideia de que se pode trazer ao presente linguagens do passado uma vez que a série de premissas e supostos em que se fundavam (que incluem visões da natureza, ideias da temporalidade, etc.) quebraram-se definitivamente. Para fazer a história das linguagens é necessário, pois, não só ultrapassar a instância textual, o plano semântico dos discursos, e tentar acessar os modos de sua produção, tratando de reconstruir contextos de debate através do reconhecimento dos rastros deixados no discurso por meio de suas condições de anunciação. Devemos, ademais, indagar os umbrais que determinam a sua historicidade, aquilo que lhes confere um princípio de irreversibilidade temporal imanente, tornando

\footnotetext{
33 Isso, não obstante, não é um fenômeno usual, senão que geralmente expressa situações de profunda crise política ou social. Como assinala José Luis Villacañas, o pressuposto da consistência da norma encontra-se na base da própria noção de legitimidade: "A legitimidade, como conjunto de crenças tidas como válidas, reclama uma representação consciente dos padrões normativos aceitos e vigentes em uma sociedade ou grupo determinado. A tese diria que a legitimidade deve ter uma dimensão reflexiva, autoconsciente, aceita tanto pelos que mandam como pelos que obedecem, e que, justamente por essa crença comum, a
}

impossível toda projeção tanto prospectiva como retrospectiva.

5. Finalmente, o segundo aspecto que faz das linguagens políticas formações históricas contingentes, e as distingue assim dos "sistemas de ideias", remete ao que podemos denominar o princípio de incompletude constitutiva das linguagens políticas modernas. Estas, diferentemente dos "tipos ideais", nunca são entidades logicamente integradas e autoconscientes. Como vimos, no seu centro encontra-se um núcleo vazio deixado pela quebra das antigas cosmologias. Daí por que nenhuma categoria política moderna possa fixar seu sentido, que elas possam, eventualmente, "ser refutadas", e não apenas ter o seu sentido modificado. De fato, nenhuma mudança semântica, nenhuma nova definição põe em crise uma determinada forma de discursividade política senão na medida em que torna manifestos os seus pontos cegos inerentes. ${ }^{33}$

Em suma, para fazer a história das linguagens não só devemos ultrapassar o plano semântico dos discursos, a fim de acessar o dispositivo formal que lhes subjaz, tratando de reconstruir contextos de debate, rastreando nos próprios discursos as pegadas linguísticas de suas condições de anunciação; inclusive não basta indagar os umbrais que determinam a sua historicidade e conferem a eles um princípio de irreversibilidade temporal imanente. É necessário - e é este o ponto crucial - compreender como é que a temporalidade irrompe eventualmente no pensamento político, como, ocasionalmente

ordem política tem vigência empírica do ponto de vista da praxis social", em José Villacañas, "Histórica, historia social e historia dos conceitos políticos", Res publica, VI: 11-12, 2003, P. 91. Acrescentemos que esse é também o pressuposto que o historiador não pode compartilhar, ou deve, ao menos, por provisoriamente entre parênteses, caso pretenda escrever uma história política que seja algo mais do que o relato que a própria comunidade pode oferecer de si, isto é, simplesmente replicar a série de idealizações que constituem tal comunidade. 
(sendo esse o caso), circunstâncias históricas precisas tornem manifestas aquelas aporias inerentes a uma forma de discursividade dada, deslocando-a. Não é outro, enfim, o objeto que dá origem à profunda renovação teórico- epistemológica, segundo assinala Pocock na citação que serve de epígrafe a este trabalho, que vem experimentando a disciplina nas últimas décadas.

\section{REFERÊNCIAS}

ALAMÁN, Lucas; INCLÁN, Luis Gonzaga. Defensa del ex-Ministro de Relaciones d. Lucas Alaman, en la causa formada contra él y contra los ex-Ministros de Guerra y Justicia del Vice-Presidente d. Anastasio Bustamante: con unas noticias preliminares que dan idea del orígen de esta. Documentos Diversos. (Inéditos e muito raros). México: Jus, 1945. Tomo III.

BALL, Terence. Confessions of a conceptual historian. Finnish Yearbook of Political Thought, Jyväskylä, v. 6, n. 1, p. 11-31, 2002.

BALL, Terence; POCOCK, John Greville Agard. (orgs.). Conceptual Change and the Constitution. Lawrence: Kansas University Press, 1998.

BEVIR, Mark. ¿Hay problemas perennes en teoría política? Res publica, Madri, num. 11-12, p. 7-26, 2003.

BIRAL, Alessandro. Per una storia del moderno concetto di politica: genesi e sviluppo della separazione tra politico e sociale. Pádua: CLEUP, 1977.

CHIGNOLA, Sandro. Historia de los conceptos, historia constitucional, filosofía política. Sobre el problema del léxico político moderno. Res publica, Madri, num. 11-12, p. 27-67, 2003.

CONNOLLY, William. The terms of political discourse. Princeton: Princeton University Press, 1983.

DUSO, Giuseppe (ed.). Il potere: per la storia della filosofia politica moderna. Roma: Carocci, 1999. . La logica del potere: storia concettuale come filosofia politica. Roma: Latterza, 2007.

FISH, Stanley Eugene. Is there a text in this class? The authority of interpretive communities. Cambridge: Harvard University Press, 1980.

GUERRA, François-Xavier. Los espacios públicos en Iberoamérica: Ambigüedades y problemas. Siglos XVIII-XIX. México: Fondo de Cultura Economica, 1998.

. Modernidad e independencias. Ensayos sobre las revoluciones hispânicas. México: Fondo de Cultura Economica, 1993

KOSELLECK, Reinhart. The historical-political semantics of asymmetric counterconcepts. In: Futures past: On the semantics of historical time. Cambridge: The MIT Press, p. 159-197, 1985.

LACLAU, Ernesto. New Reflections on the Revolution our Time. Londres: Verso, 1990.

MOSTERÍN, Jesús. Conceptos y teorías en la ciencia. Alianza, 1984. 
NORIEGA, Alfonso. El pensamiento conservador y el conservadurismo mexicano. México: UNAM, 1993.

PALTI, Elías José. La invención de una legitimidad: razón y retórica en el pensamiento mexicano del siglo XIX: un estudio sobre las formas del discurso político. México: Fondo de Cultura Economica, 2005.

. La Política Del Disenso: La Polémica en Torno Al Monarquismo México, 1848-1850. México: Fondo de Cultura Economica, 1998.

POCOCK, John Greville Agard. Introduction: the state of the art. In: Virtue, Commerce, and History. Essays on political thought and history, chiefly in the eighteenth century. Cambridge: Cambridge University Press, 1991.

Politics, language, and time: Essays on political thought and history. Chicago: University of Chicago Press, 1989.

The Machiavellian moment: Florentine political thought and the Atlantic republican tradition. Princeton: Princeton University Press, 1975.

- Virtue, commerce, and history: Essays on political thought and history, chiefly in the eighteenth century. Cambridge: Cambridge University Press, 1976.

ROSANVALLON, Pierre. Por una historia conceptual de lo político: lección inaugural en el Collége de France. Buenos Aires: Fondo de Cultura Económica, 2003.

SÁNCHEZ DE TAGLE, Francisco Manuel. Refutación de las especies vertidas en los números 21, 22, 23 del periódico titulado El Anteojo contra el proyecto de la primera ley constitucional, que presentó al Congreso la Comisión de Reorganización. México: Imprenta del Águila, 1835.

SCHIERA, Pierangelo (org.). Per una nuova storia constituzionale e sociale. Nápoles: Vita e Pensiero, 1970.

SCHIERA, Pierangelo. Otto Hintze. Nápoles: Tecniche Nuove, 1974.

VEIT-BRAUSE, Irmline. The Interdisciplinarity of History of Concepts. A Bridge Between Disciplines. History of Concepts Newsletter, Nova Iorque, 6, p. 8-13, 2003.

VILLACAÑAS, José. Histórica, historia social e historia dos conceitos políticos. Res publica, Madrid, num. 11-12, p. 69-94, 2003. 
